\title{
A imprensa turística como um dos veículos de turistização do território português nas décadas de 1930 e de 1940: O caso da revista Turismo
}

\section{The tourist press as a one of the touristization vehicles of the Portuguese territory in the 1930 s and 1940s: The case of Turismo magazine}

\author{
Manuel Tojal \\ Instituto Politécnico da Maia, Núcleo de Investigação do Instituto Politécnico da Maia \\ mdtojal@sapo.pt
}

\begin{abstract}
Resumo
A revisão da literatura mostra que a turistização do território português nos anos trinta e quarenta do século XX foi feita sobretudo graças à política de expansão da rede ferroviária e aos melhoramentos introduzidos na rede rodoviária. O que este artigo procura demonstrar é que a imprensa turística, através de uma persistente ação de "propaganda" das cidades e das vilas, das montanhas e das aldeias, das praias e das termas de Portugal, difundida por meio de uma retórica de exaltação exacerbada dos seus valores turísticos, constituiu um veículo coadjuvante dessa expansão geográfica dos lugares. Começando por fazer uma resenha do que foram as revistas especializadas emergentes nesse lapso temporal, o artigo concentra-se posteriormente nas estratégias de "propaganda" utilizadas pela revista Turismo (1936-1953), no sentido de estimular o alargamento progressivo desses lugares turísticos, procurando apresentá-los como destinos apetecíveis e contribuindo, desse modo, para a referida turistização do território.
\end{abstract}

Palavras-chave: Turistização; imprensa turística; estratégias de propaganda; roteiros turísticos; revista Turismo.

\begin{abstract}
The literature review shows that the touristization of the Portuguese territory (meaning the geographical expansion of tourist places) in the 1930 s and 1940 s resulted mainly from the policy of expanding the railway network and from the improvements introduced in the road network. What this paper seeks to demonstrate is that the tourist press, through a persistent "propaganda" of cities and towns, mountains and villages, beaches and spas in Portugal, disseminated through an exaggerated rhetoric of exaltation of their touristic values, was a supporting vehicle for this geographical expansion of places. Starting with a review of the specialized magazines that emerged during this period of time, the paper then focuses on the advertising strategies used by the Turismo magazine (1936-1953) to stimulate the progressive expansion of these places, aiming to present them as desirable destinations and thus contributing to the aforementioned touristization of the territory.
\end{abstract}

Keywords: Touristization; tourist press; advertising strategies; tourist routes; Turismo magazine.

Dos Algarves: A Multidisciplinary e-Journal, 39-2021.

ISBN 2182-5580 @ ESGHT - University of the Algarve, Portugal.

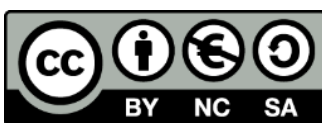

To cite this article: Tojal, M. (2021). A imprensa turística como um dos veículos de turistização do território português nas décadas de 1930 e de 1940: O caso da revista Turismo. Dos Algarves: A Multidisciplinary e-Journal, 39, 37-51. DOI: 10.18089/DAMeJ.2021.39.3 


\section{Introdução}

Se é certo que já durante a $1 .{ }^{a}$ República era a rede ferroviária nacional que "provia boa parte das deslocações dos portugueses para fins turísticos" (Ferreira \& Simões, 2010: 82), na 2. República essa importância da ferrovia viria a acentuar-se. Alguns autores (Matos, Ribeiro \& Bernardo, 2009; Ribeiro, 2017) sustentam mesmo que a efetiva turistização do território português, centrada em localidades pitorescas do ponto de vista etnográfico e relevantes do ponto de vista histórico-cultural, foi uma tarefa levada a cabo sobretudo pelo regime do Estado Novo, muito graças à expansão da rede ferroviária que foi condicionando de forma clara o desenvolvimento turístico nacional ao potenciar os fluxos, tanto internos como externos, para os diferentes lugares/estâncias turísticas de Portugal. Recentemente, a historiadora Magda Pinheiro veio, no entanto, contrariar esta tese da importância decisiva da rede ferroviária no incremento do turismo durante o regime estadonovista. Com efeito, apesar da construção de algumas centenas de quilómetros de ferrovia entre 1933 e 1953, o caminho-de-ferro, tal como a mesma sublinha, começou a tornar-se "obsoleto" a partir do momento em que Salazar e Duarte Pacheco se deixaram fascinar pela modernidade do automóvel. A citada autora vai ao ponto de afirmar que o Estado Novo "foi completamente anticomboio", apostando claramente no alargamento da rede rodoviária (Pinheiro, 2020: 49). Sem a pretensão de se enveredar aqui pelo aprofundamento desta polémica, o objetivo deste estudo passa por tentar demonstrar a relevância que a imprensa turística teve como veículo coadjuvante dessa turistização do território através da sua persistente ação de "propaganda" das cidades e das vilas, das montanhas e das aldeias, das praias e das termas, dos distritos e das regiões deste país. Do mesmo modo, no que toca à sua projeção internacional, considera-se válida a opinião de Maria João Castro, segundo a qual a publicação de revistas especializadas na área do turismo foi, desde o surgimento da Revista de Turismo em 1916, um dos instrumentos que contribuíram para a promoção de Portugal na geografia euro-americana e para o desenho do "novo cartão-postal do turismo da nação que "deu novos mundos ao mundo"”' (Castro, 2014: 42).

O conceito de turistização deve aqui demarcar-se claramente da conotação predominantemente negativa atribuída ao termo turistificação, entendido como sinónimo da transformação que a atividade turística traz a um determinado destino, com consequências não apenas no património edificado por causa da forte pressão urbanística, muitas vezes descaracterizadora da paisagem, mas também na transformação mental e comportamental resultante da relação entre turistas e residentes. Com o termo utilizado no título deste artigo, procura traduzir-se a expansão da geografia dos lugares turísticos em Portugal, para a qual contribuíram não apenas as redes ferroviária e rodoviária, mas também, como iremos tentar demonstrar, a persistente ação de "propaganda" veiculada pela retórica da exaltação exacerbada dos valores turísticos nacionais presente nos editoriais, nos artigos de fundo, nas crónicas, na publicidade e nas imagens das revistas especializadas dos anos trinta e quarenta do século XX. Com efeito, a imprensa turística teve - e continuará a ter - um papel preponderante na divulgação da riqueza do nosso património, da nossa história, da nossa gastronomia ou da nossa geografia, exercendo uma grande influência na formação da opinião pública e, consequentemente, na escolha dos destinos. 
Neste contexto, considerou-se pertinente proceder a uma pesquisa que permita verificar até que ponto a imprensa turística terá funcionado como um dos veículos de turistização do território português no arco temporal compreendido entre o início da década de 1930 e o final da década de 1940. O corpus documental compreende, à partida, as seguintes publicações periódicas especializadas: A.C.P.: Revista llustrada de Automobilismo e Turismo (1930-1947); ' Turismo: Revista de Hoteis, Viagens e Actualidades (1. ${ }^{a}$ série, 1936-1953); Viagem: Revista de Turismo, Divulgação e Cultura (Porto, 1938-39; Lisboa, 1940-65); Panorama: Revista Portuguesa de Arte e Turismo (1. a série, 1941-49). Atendendo, no entanto, à necessidade de delimitação desse mesmo corpus, a opção para o estudo da questão fulcral de investigação recaiu eminentemente sobre a revista Turismo. Esta escolha justifica-se não apenas pelo volume dos números consultados, correspondentes a um lapso temporal de 17 anos, mas também pelo facto de, ao contrário dos outros periódicos mencionados, serem inexistentes os estudos sobre esta publicação que atravessa grande parte do consulado salazarista.

Neste artigo, de carácter predominantemente teórico e histórico, colocam-se algumas questões de investigação que se prendem com a hipótese atrás formulada: A que públicoalvo se destinava a revista Turismo? Quais os principais roteiros de viagem nela sugeridos? Que estratégias de propaganda turística foram aí utilizadas?

Em termos metodológicos, optou-se preferencialmente pelo método indutivo através da análise de conteúdo dos editoriais, dos artigos de fundo, das crónicas, das entrevistas, das reportagens ou das propostas de roteiros provenientes, nomeadamente, da revista Turismo, com aplicação do método comparativo sempre que se trata de estudar os conteúdos presentes nos diferentes periódicos.

\section{Revistas especializadas na área do turismo nas décadas de 1930-1940}

No lapso temporal em estudo, merecem registo, como acima foi referido, quatro publicações periódicas que, mais ou menos diretamente ligadas à área do turismo, fizeram a sua história e, conforme tentaremos demonstrar, contribuíram para a expansão dos lugares turísticos em Portugal e para a sua projeção além-fronteiras.

Em janeiro de 1929, a direção do Automóvel Club de Portugal (ACP) decidiu iniciar a publicação do seu Boletim Oficial. Manteve-se este periódico durante vinte e um meses, após o que, "carecendo de alargar a sua esfera de acção, passou à categoria de Revista llustrada de Automobilismo e Turismo, tratando desenvolvidamente nas suas colunas de todos os assuntos relacionados com o automobilismo, tanto nacional, como internacional" ("O $15 .{ }^{\circ}$ ano da revista A.C.P.", 1945: 3). O seu $1 .^{\circ}$ número saiu em novembro de 1930, devendo referirse que, a partir do.$^{\circ} 28$, publicado em janeiro de 1933 , o título surge na capa com uma pequena mas significativa alteração, passando o termo "turismo" a preceder

\footnotetext{
1 Tendo abandonado em 1947 o subtítulo Revista llustrada de Automobilismo e Turismo, esta publicação, nomeadamente a partir de 1950, alterou significativamente os seus conteúdos, focando-se quase exclusivamente na indústria automóvel e nas provas automobilísticas.

${ }^{2}$ A partir do n. ${ }^{\circ} 39$ (março-abril de 1941), este periódico suprime o subtítulo, passando a intitular-se simplesmente Revista Turismo.
} 
"automobilismo" (A.C.P.: Revista de Turismo e Automobilismo), embora na página do Editorial se tenha mantido o título anterior. A partir de 1947, com periodicidade bimestral, esta publicação passaria a intitular-se simplesmente ACP. Pela importância nele atribuída ao setor do turismo, o órgão oficial do ACP enquadra-se perfeitamente dentro da imprensa da especialidade, vindo a ser contemporâneo das revistas Turismo, Viagem e Panorama. Aliás, no contexto de desenvolvimento da indústria turística na década de 1930, não é de estranhar que mesmo a imprensa não especializada tivesse constituído um importante espaço de debate do turismo nacional.

Apesar da sua propalada independência do poder político, o certo é que o ACP e, consequentemente, o seu órgão de comunicação oficial, sempre contaram no seu seio com figuras ligadas ao regime, o que viria a acentuar-se após a criação do Estado Novo. O slogan "A Bem da Nação", com as suas variantes "Para o Bem da Nação" ou "Em Pról da Nação", está presente tanto no discurso propagandístico do regime de Oliveira Salazar como nos discursos do presidente do ACP, Engenheiro Carlos Santos: "É preciso lembrarmo-nos do que o A.C.P. tem produzido a bem da Nação, prestando aos poderes públicos a mais leal e a mais activa colaboração noutros sectores interessando ao desenvolvimento do turismo" "“A visita do Director do Secretariado de Propaganda Nacional...", 1933: 8). Em 1936, o mesmo Carlos Santos, em carta dirigida a Salazar a propósito da reunião em Lisboa da Comission Internationale de Tourisme, referia abertamente o seu incondicional apoio à política do regime nos seguintes termos: “O Automóvel Clube de Portugal, pode Vossa Excelencia estar seguro, não perderá um único ensejo para conseguir que todos eles [os automobilistas estrangeiros] saiam de Portugal com a mais lisonjeira das impressões e se convertam nos melhores propagandistas do valôr turístico do nosso País" (Santos, como referido em Cadavez, 2017: 168).

Em abril de 1936, em Lisboa, surge em a publicação Turismo: Revista de Hoteis, Viagens e Actualidades. Dirigido por António Pardal, este periódico que, na sua 1. ${ }^{\text {a }}$ série, se publicou sem interrupção até novembro de 1953, perfazendo um total de 107 números, surge com o propósito de suprir uma lacuna no setor, depois da experiência que, nos primórdios da República, constituiu a Revista de Turismo, referenciada como "publicação quinzenal, de turismo, propaganda, viagens, navegação, arte e literatura”, ao longo de 141 números, entre julho de 1916 e março de 1924. É possível, aliás, estabelecer facilmente um paralelismo entre os termos utilizados nesta última para definirem Portugal, classificado como "paiz excessionalmente talhado para o turismo", com uma situação geográfica de tal forma privilegiada que não havia no mundo outro "com tão boas condições naturaes para o turismo" (Maio, 1916: 63) e aquilo que se pode ler no primeiro editorial da Turismo onde Portugal surge "sem qual dúvida" como "um Paiz excepcionalmente dotado para a indústria do turismo", com "belezas naturais das mais raras, monumentos dignos da curiosidade mais exigente, um clima invejável, céu da mais pura transparência - tudo, enfim, quanto pode fazer as delícias dum viajante habituado ao grande mundo" ("Porque vimos", 1936: 2). Assumindo claramente o propósito de se votar à "propaganda turística do país", a direção da revista chega a cometer o exagero de afirmar no referido Editorial, escrito e publicado em 1936, que este periódico "se julga no dever de chamar a si a missão importante de que, até à data, nenhuma outra revista quis desempenhar-se entre nós, na latitude e com a eficiência 
que seria para desejar" ("Porque vimos", 1936:2). Em fevereiro de 1937, no seu n. ${ }^{\circ} 6$, Turismo publicitava em inglês a particularidade de ser "the only Portuguese monthly on the subject, reaching all Europe and the Americas", fazendo igualmente um apelo em francês aos proprietários dos hotéis e pensões no estrangeiro para as vantagens de inserirem publicidade neste periódico, "puisque c'est la revue portugaise de la spécialité de plus gros tirage et de plus large expansion" ("Publicité dans «Turismo»", 1937: 16). Sem nunca se fazer uma alusão precisa à tiragem, ${ }^{3}$ escreve-se nessa mesma página que, durante a Exposição Internacional de Paris, à qual a revista consagra o seu número 8 , "y seront distribués gratuitement des milliers d'exemplaires". A propósito da presença de línguas estrangeiras nas páginas da revista, refira-se a intenção, enunciada no seu primeiro Editorial, de recorrerem "frequentemente, ao francês, ao inglês, ao espanhol, ao alemão, enfim, a qualquer língua que, de algum modo, possa levar a toda a parte uma referência a Portugal, às suas belezas e à sua gente" porque "desejamos que a nossa acção vá além das fronteiras lusitanas" com o objetivo de que os estrangeiros "nos procurem com mais frequência e com mais viva simpatia" ("Porque vimos", 1936: 2). Tal enunciação de objetivos pressupõe que esta publicação se destinava não apenas ao público interno, mas também ao leitor estrangeiro dos "países que nos são mais afins ou que, por qualquer motivo, devam ser esclarecidos sôbre o que sômos turìsticamente" ("Porque vimos", 1936: 2). No que toca ao público interno, constata-se que a revista privilegia o leitor citadino e, mais especificamente, lisboeta. No discurso que vai percorrendo as suas páginas, a certa altura, o arranjo, a limpeza e a salubridade dos "recantos pitorescos, e até históricos, de pequeninas vilas e aldeias antigas", em vez de surgirem como exigências postas ao serviço dos seus habitantes, parecem ser requeridos sobretudo para o enlevo dos citadinos quando por elas passam "ao acaso, numa corrida de automóvel”, ou quando as adivinham das janelas do comboio: "Manter-lhes a graça original, o encanto simples e as tradições, sim, mas limpá-las um pouco mais, dar-lhes mais higiene e utilizar o seu encanto natural para as excursões dos homens da cidade que ali iriam aprender a simplicidade da vida rústica" ("A poesia da vida rústica ao serviço do Turismo", 1946: n.p. - itálico nosso). E logo no $1 .^{\circ}$ número da revista, numa interpelação que traz imediatamente à memória o "leitor amigo" do Garrett das Viagens, surge reiteradamente como destinatário de uma crónica jornalística o "lisboeta amigo", instado a ir além de Sintra, de Palmela e da Arrábida para conhecer a grandiosidade do Douro e de Trásos-Montes (Braga, 1936: 13), no intuito de aí encontrar, como diria Sampaio (2012: 101), "imagens de um Portugal atemporal de paisagens estetizadas e de camponeses transformados em jardineiros da paisagem", para consumo de turistas e visitantes e, por essa via, ao serviço da visão ruralista e folclorista do regime.

Tal como já havia acontecido e viria a acontecer nas páginas das suas congéneres, o discurso prevalecente na revista Turismo vai, assim, inteiramente ao encontro da visão estética desenhada pela propaganda salazarista, inspirada na "política do espírito" preconizada por António Ferro e, segundo a qual, importa associar o bem ao espírito e o mal

\footnotetext{
${ }^{3}$ A menção explícita à tiragem (22.000 exemplares) surgirá pela primeira vez no 1. ${ }^{\circ}$ número da 2. ${ }^{a}$ série (out.-nov. 1954), numa altura em que este periódico adquire uma nova feição e um novo subtítulo (Turismo: Revista de arte, paisagem e costumes portugueses).
} 
à matéria, o que implica uma assimilação do real ao sujo, ao impuro e do espírito ao limpo, ao asseado. Como refere Santos (2008: 62), "para serem bem vistas pelo Estado Novo, as formas artísticas estarão proibidas de se debruçarem demasiado sobre a realidade social do país que deverá sempre ser apresentado como sendo um universo harmonioso e alegre". Paradigmático se torna a este nível o seguinte trecho da rubrica "Crónica do Turismo", assinada por Julião Quintinha e publicada em agosto de 1940 a propósito dos encantos do Minho:

Se o Minho possui da mais bela paisagem; se encontramos ali monumentos coevos e anteriores à Nacionalidade; se o folclore minhoto rescende flores e resume a mais fina inspiração popular; se a família é hospitaleira e a terra dá frutos, vinho e pão; se a vida moderna começa a insuflar a terra minhota de todos os confortos, embelezando vilas e cidades, melhorando as vias de comunicação, dando um ar de novidade e graça às suas estâncias, termas e hotéis - eis que o Minho disfruta [sic], vantajosamente, a primazia dos encantos turísticos entre as outras regiões portuguesas. (Quintinha, 1940: s.p.)

A ideologia do belo que se opõe ao verdadeiro olvida aqui intencionalmente a realidade que colidia com esta paisagem bucólica, desmascarada alguns anos mais tarde por Eugénio Castro Caldas, na sequência do Inquérito à Habitação Rural realizado entre 1955 e 1960. Aí se pode ler, a propósito desta mesma região do Minho, que as suas aldeias, embora situadas numa "paisagem rica de tons verdes e frescura de água", constituem conjuntos de aspeto pobre, senão miserável. Retalhados de caminhos de piso irregular, que servem de passagem a homens e animais e de recreio a "crianças sujas, piolhosas e assustadiças que precocemente saem do berço, a gatinhar, para acompanhar porcos e galinhas", estes aglomerados populacionais "oferecem o espectáculo de quase todas as condições de que os homens se rodeavam em tempos primitivos" (Caldas, como referido em Leal, 2009). Como é compreensível, esta narrativa altamente disfórica nunca teria passado no crivo da Comissão de Censura que, incansavelmente, vigiava todas as publicações periódicas da época.

Refira-se que a revista dirigida por António Pardal, com periodicidade irregular (mensal, passando a bimestral e, por vezes, a trimestral), classificada pelo Diário da Manhã como "a melhor entre as congéneres" ("Número Especial de Aveiro", 1943: s.p.), ${ }^{4}$ viria a ser distinguida em agosto de 1943 pelo Ateneu Comercial de Lisboa com o prémio de " 1. . Classificado" na classe de "Apresentação artística - Revistas", obtido na 1. ${ }^{\text {a }}$ Exposição Bibliográfica de Turismo e Propaganda de Portugal.

Em julho de 1938, surge nas bancas um novo periódico especializado. Trata-se de Viagem, uma publicação mensal editada na cidade do Porto com o subtítulo de Revista de Turismo, Divulgação e Cultura, sob a direção de Marques da Costa, em colaboração com a C.P. e com o patrocínio do Conselho Nacional de Turismo. Encerrada a sua publicação em agosto de 1939, o mesmo título viria a ressurgir em Lisboa no mês de novembro de 1940, sob a direção do jornalista Carlos d' Ornellas. A nova direção da revista, embora tenha adotado exatamente o mesmo título "por expressivo como nenhum outro", a mesma "feição gráfica" e a mesma “sugestiva capa” (Ornellas, 1940: 1), não assume, no entanto, o reinício da sua publicação

\footnotetext{
${ }^{4}$ Lamentavelmente, este periódico deixou de apresentar paginação a partir do $\mathrm{n} .^{\circ} 21$, mantendo-se assim até ao n. ${ }^{\circ} 72$.
} 
como uma 2. 'Série, antes preconizando que a primeira Viagem "foi considerada extinta", perdendo mesmo "o direito à garantia do título", o que lhe não dava, todavia, o direito de plagiar todo o grafismo da capa sem assumir abertamente o início de uma $2{ }^{\text {a }}$ série. Ainda assim, no Editorial desse novo $1 .^{\circ}$ número, Carlos d' Ornellas considera esta renovada Viagem como "a bem dizer irmã da que tão prematuramente caiu no limbo das coisas impressas", propondo-se reanimar a iniciativa que havia surgido no Porto e que, tendo-se apresentado como uma revista "moderna, interessante, de recheio magazinesco, dirigida aos que gostam de viajar e ainda àqueles que, por suas favoráveis condições de vida, podem adquirir êsse gosto que instrue e aristocratiza o espírito" (Ornelas, 1940: 1), fazia falta no meio português.

O cariz ideológico deste periódico revela-se francamente conservador e defensor do status quo. É-o quando se elogiam as iniciativas do Secretariado de Propaganda Nacional (SPN), como foi o caso da realização do Concurso da Aldeia Mais Portuguesa de Portugal, tão criticado por outros setores mais progressistas: "Carecem os adjectivos de valor ao se tentar definir o alcance, nacional e patriótico, de criar, como estímulo e homenagem, um prémio à aldeia portuguesa que melhor soube guardar as suas antigas características" ("O galo de Prata", 1938: 1). É-o também quando se apresenta como um veículo da ideologia que defendia a intervenção da mão mediadora do Estado na atividade turística. Conforme salienta Cadavez (2017), sob a liderança de António Ferro, a prática turística parecia permitir que "um ensinamento superior" ditasse as rotinas do turista e "classificasse e indicasse o que deveria ser visitado". Esta crença é justamente reafirmada pelo editorialista da Viagem quando, a propósito das dificuldades experimentadas pelo turista em "saber viajar", se propõe auxiliar esse "desideratum", proporcionando ao viandante que percorre Portugal uma maior parcela de encanto, orientando-o e despertando-lhe o interesse pelo desconhecido ("A 90 à hora", 1938:1).

Em 1941, surge em Lisboa Panorama. Revista Portuguesa de Arte e Turismo. Lançada pelo Secretariado da Propaganda Nacional sob a direção de António Ferro, esta revista insere-se na lógica de propaganda que havia presidido ao "Plano dos Centenários". Emergindo na sequência da Exposição do Mundo Português, realizada em 1940, a sua génese é, por conseguinte, indissociável de uma fase de forte afirmação ideológica do Estado Novo, em formatos de comunicação de massas característicos de diversos autoritarismos desse período. Partindo do princípio de que, em termos de turismo, todas as abordagens que até aí se haviam feito em Portugal "resultavam de uma mentalidade ainda ligada a conceitos oitocentistas de grand-tour" (Victorino, 208: 3) que se contentavam em "transformar algumas praias e termas em centros de vilegiatura para os privilegiados, que ali podiam encontrar versões portuguesas de Biarritz ou de Évian, fossem elas na Figueira ou em Vidago, onde pontificavam os grandes (e por vezes já obsoletos) palaces, inseridos em ambientes falsamente cosmopolitas" (Victorino, 2018: 3), António Ferro pretendia, também através desta publicação, reabilitar um país periférico perante os olhos do citadino e do estrangeiro e, simultaneamente, "reconciliar a consciência da classe média em relação a um passado de grandeza, algo que a decadência demo-liberal, a importação de novos hábitos, a entrega ao materialismo, tinham ajudado a aviltar, segundo os apóstolos do regime" (Victorino, 2018: 5). 
Num ensaio publicado em 2013, Margarida Acciaiuoli procurou fazer um esboço de categorização por temas dos artigos presentes na revista Panorama, destacando não apenas aqueles que se debruçam sobre as transformações que se operavam no território nacional e sobre a maneira como ilustravam o espírito realizador que marcava o tempo mas também aqueles que se centram nas características dos lugares e no modo como determinavam a índole do povo (Acciaiuoli, 2013: 247). José Victorino, ao fazer uma resenha do que foi a $10^{\mathrm{a}}$ série desta mesma revista (1941-1949), prossegue essa categorização, salientando:

- conjunto das chamadas "Reportagens Imprevistas" que tiveram um papel ativo na defesa do património artístico e arquitetónico, denunciando a incúria a que haviam sido votados alguns "tesouros esquecidos";

- os artigos que fazem o levantamento de uma "reserva estratégica" de locais ainda em estado virgem que pudessem vir a constituir-se como novas referências no ainda rudimentar mercado turístico português;

- os artigos focados na motivação do turista para visitar os lugares mais autênticos e mais pitorescos, na linha da retórica salazarista;

- a faceta inovadora da revista Panorama no apelo reiterado à prática do campismo, modalidade ainda pouco divulgada em Portugal;

- seu pioneirismo na previsão de que o Algarve possuía condições para se vir a transformar numa estância de turismo internacional (Victorino, 2018).

No que diz respeito a este último tópico, não podemos estar de acordo com Victorino na medida em que, antes desta publicação, já a revista Turismo, em abril de 1936, havia chamado a atenção para "todos os aspectos e graças naturais" de "um dos mais belos lugares do mundo", os quais "concorrem para fazer do Algarve a região ideal do Turismo" (Quintinha, 1936: 8). A perspetiva da transformação em estância de turismo internacional seria mais explicitamente formulada em janeiro de 1937 quando o articulista afirma justificadamente que o Algarve possui "condições para ser um grande centro mundial de turismo" (Correia dos Santos, 1937: 6). No que toca aos apelos à prática do campismo, encontramo-los também com relativa frequência a partir de 1944 na revista Turismo. Um bom exemplo disso mesmo é o artigo onde se considera como muito saudável e oportuna "a campanha que anima e orienta o movimento de campismo que se esboça em Portugal", prescrevendo-se a prática campista como a melhor terapia para fazer esquecer a "neurastenia da cidade" (“Façam campismo, rapazes e raparigas de Portugal”,1944: s.p.). E em dois números consecutivos, Armando Faia $(1944 ; 1945)$ apresenta uma curiosa tipologia das modalidades já nessa época relacionadas com esta prática, do campismo pedestre ao campismo náutico, passando pelo ciclo-campismo, auto-campismo e campismo hípico.

Mesmo na categoria dos artigos que se debruçam sobre as características dos lugares e a forma como determinavam a índole do povo português, já antes da Panorama a revista Turismo publicava interessantíssimos artigos acerca desta matéria.

Quando no texto da Mostra "Viagens pela Escrita e pelo Cartaz: 100 anos de Turismo em Portugal” se afirma que, a partir dos anos 70 do século XX, a imprensa turística se interessou em "editar guias e roteiros, propondo circuitos, quase sempre incluindo plantas e mapas, 
com a informação geográfica e cartográfica mais relevante para o turista, e anúncios de publicidade de estabelecimentos hoteleiros, termais e comerciais, de indústrias e empresas de transportes" (Comissão Nacional do Centenário do Turismo em Portugal, 2011), parece estar a esquecer-se aí completamente o trabalho já realizado a partir de 1936 pela revista Turismo que, desde o seu primeiro número, propõe circuitos incluindo plantas e mapas e apresentando sistematicamente anúncios publicitários de "hotéis portugueses que se recomendam" (especificando em inglês Localities, Class., Number of Bedrooms e PriceRooms), mas também anúncios de "pensões e restaurantes recomendados", desde Valença até Sagres.

\section{A imprensa turística como um dos veículos de turistização do território português}

Dentro da estratégia de "propaganda turística" delineada pela imprensa especializada neste setor, nomeadamente no caso da revista Turismo, importa começar por destacar a utilização das cartografias.

No seu segundo número, ainda que de forma pouco rigorosa porque não correspondente à classificação efetuada em 1918, o citado periódico insere uma ilustração intitulada "Distancias em kilometros de Lisboa a's terras de turismo" (1936: 22), na qual a capital surge estrategicamente colocada como foco irradiador para 50 lugares turísticos de norte a sul do país. Em termos estratégicos, pode dizer-se que não terá sido este o melhor começo, uma vez que era necessário que essa "propaganda" fosse muito para além das 65 famigeradas "terras de turismo" de $1{ }^{\text {a }}$ ou $2 .{ }^{\text {a }}$ classe, definidas por razões tributárias em 1918 e às quais foram acrescentadas mais 5 em diploma legal de fevereiro de 1919 (Vila do Conde, S. João do Estoril, Parede, Caramulo e Cai Água). Também a revista Viagem, logo no seu primeiro número, insere uma ilustração intitulada "Porque não conhece Portugal?" (1938:3) na qual se propõem 34 lugares ou regiões dignas de visita. Neste caso, a cartografia desses itinerários é contextualizada com um conjunto de pictogramas associados a símbolos que, nalguns casos, passariam a fazer parte do imaginário turístico ligado a cada um deles (o barco rabelo no rio Douro, o esquiador na Serra da Estrela, o pescador da Nazaré, o campesino do Ribatejo) e que privilegiam o património construído e imaterial (monumentos e artefactos). ${ }^{5}$

A partir de 1937, serão publicitadas na revista Turismo cartografias relacionadas com "Praias de Portugal" (52 praias), "Centros de Repouso e Prazer" (43 centros) e "Termas de Portugal" (54 termas). Interessante se torna mencionar os lugares ou regiões que figuravam nessas ilustrações na categoria de "Centros de Repouso e Prazer" (1937: 20): Monção, Caminha, Gerês, Barcelos, Pedras Salgadas, Guimarães, Beiriz, Vizela, Régua, Vouzela, Aveiro, Gouveia, Guarda, Bussaco, Caramulo, Manteigas, Arganil, Covilhã, Pombal, Figueiró dos Vinhos, Serra da Estrela, Castelo de Vide, Portalegre, Óbidos, Peniche, Colares, Sintra, Lisboa, Costa do Sol, Arrábida, Setúbal, Moura, Monchique, Praia da Rocha, Lagos, Loulé, Tavira, Faro, Vila Real de Santo António, Madeira e Açores. Com a intenção de alargar à rede viária a referida influência exercida pela expansão da ferrovia, a publicidade a empresas de

5 Quase duas décadas depois, o n. 2 do anuário Portugal País de Turismo (1954) publicaria um documento intitulado "Excursões em Portugal" que cartografa um conjunto de 62 lugares com pictogramas sobrepostos apresentando, como seria de esperar, um nível de estilização qualitativamente bastante superior. 
camionagem para transporte de cargas serve de pretexto para se apresentar "O Mapa Turístico de Portugal" (1945: s.p.), com o intuito de evidenciar "quanto andam estreitamente ligados Turismo e Automobilismo". A esta maior incidência de publicitação do citado Mapa Turístico (ligado à rede viária) não será estranha a política de incremento da utilização do automóvel provinda das opções do regime que, num dos sete famosos cartazes da série propagandística intitulada “A Lição de Salazar", editada em 1938, exaltava a substituição dos "intransitáveis caminhos" por "magníficas estradas" que passaram a cortar Portugal "de lés a lés". A apologia do rejuvenescimento do país e o elogio da obra feita ou em vias de execução estão bem patentes no seguinte Editorial de 1939: "O recente plano de estradas de turismo a efectuar este ano pelo Ministério das Obras Públicas e Comunicações, que no corpo de técnicos da Junta Autónoma das Estradas tem a sua perfeita execução, leva-nos, em estradas largas, a admirar a obra dos tempos, desde as serras brancas que se confundem com as núvens, até às areias doiradas de riba-mar" ("Estradas de turismo e as comemorações do duplo centenário", 1939: s.p.).

Ainda no domínio das cartografias, merece igualmente destaque na revista Turismo a publicação de Roteiros turísticos regionais, habitualmente acompanhados de representações pictográficas. Citem-se os casos de "Oito excursões em volta de Lisboa" ( $n .{ }^{\circ}$ 2), "Itinerário Turístico de Aveiro" (n. $\left.{ }^{\circ} 51\right)$, "Roteiro Turístico de Leiria" (n. ${ }^{\circ}$ 54), "Roteiro Turístico do Ribatejo" (n. ${ }^{\circ}$ 55), "Itinerário Turístico do Distrito de Setúbal” (n. $\left.{ }^{\circ} 59\right)$, "Roteiro Turístico de Santarém” (n. $\left.{ }^{\circ} 61\right)$, "Excursões em volta de Évora” (n. $\left.{ }^{\circ} 64\right)$ e "Roteiro Turístico do Algarve (n. 82) (v. Figura 1).

Figura 1. Roteiros turísticos regionais insertos na revista Turismo
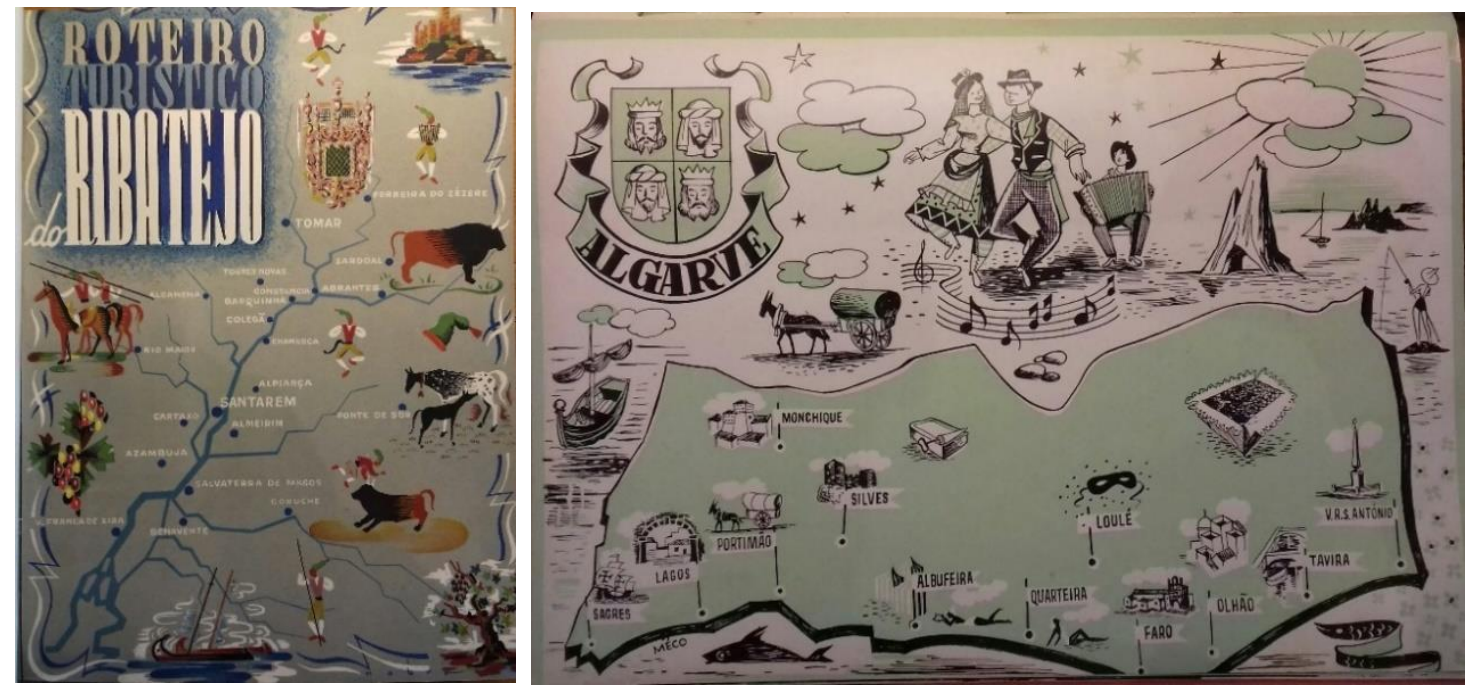

Fonte: Turismo, n. ${ }^{\circ}$ 55, nov.-dez. 1944; Turismo, n. ${ }^{\circ}$ 82, fev. 1949, p. 30.

Uma outra estratégia de "propaganda", necessariamente menos imediatista para o leitor, passa pela sugestão de roteiros turísticos baseados exclusivamente na componente textual. Seguindo a lógica de "O que deve ser visto em..." (que imediatamente nos remete 
para a fórmula utilizada no célebre guia de Fernando Pessoa redigido em 1925, mas só publicado em 1992 com o título Lisboa: O que o turista deve ver / What the tourist should see), esses textos podem estruturar-se em pequenas secções que pretendem orientar o turista para "Monumentos", "Museus", "Parques e jardins" e "Excursões recreativas", como é o caso de "O que deve ver-se em Coimbra" (1944: s.p.). Por vezes, seguindo modelos já utilizados em documentos promocionais editados em 1915 e 1918 pela Sociedade Propaganda de Portugal (Portugal: Clima, Paisagens, Estações Thermaes, etc.), os redatores optam pela retórica da exaltação exacerbada dos valores turísticos nacionais, num discurso hiperbolizante e eufórico. Nalguns casos, os cronistas revelaram mesmo uma aguda perceção do registo verbal e da retórica utilizados nos seus textos de "exaltação turística", como no exemplo seguinte referente à região de Setúbal:

\begin{abstract}
E a verdade é que Setúbal, com a magnificente região que a circunda, reúne, sem favor, condições excepcionais para vir a impor-se como verdadeiro centro de turismo internacional. Não lhe falta nenhum dos lugares comuns indispensáveis numa crónica de exaltação turística. A beleza estonteante da paisagem e a amenidade do clima; os panoramas imprevistos, que surgem, como nas mágicas, quási por encanto, lugares edénicos e de visões paradiśacas, em recantos de sonho e maravilha; caminhos frondosos de beleza surpreendente, aquietados por sombras acolhedoras e suaves estas legendas de oiro tem-nas Setúbal e os seus arredores magníficos, num cenário de enquadramento empolgante. (Rocha, 1944: s.p., itálico nosso)
\end{abstract}

Desde cedo a revista Turismo envereda por uma via monotemática, com números consagrados a um só distrito ou a uma só região. O cuidado posto na realização desses números, alguns dos quais chegaram a atingir o extraordinário volume de 300 páginas, implicava a utilização de papel com gramagem especial que permitisse a boa qualidade de impressão de documentos fotográficos e capas a cores, para além da colaboração de “ilustres escritores e artistas" (“Crónica do Turismo", 1944: s.p.). Vale a pena referir os números especiais dedicados a Bragança (n. ${ }^{\circ}$ ), Algarve (n. ${ }^{\circ} 17, n .^{\circ} 45$ e n..$\left.^{\circ} 82\right)$, Braga (n..$\left.^{\circ} 35\right)$, Santarém (n. $\left.{ }^{\circ} 36\right)$, Minho (n..$^{\circ} 8$ ), Guarda (n..$\left.^{\circ} 43\right)$, Aveiro (n. 51 e n. ${ }^{\circ}$ 95), Leiria (n. $\left.{ }^{\circ} 54\right)$, Coimbra (n. $\left.{ }^{\circ} 56\right)$, Setúbal (n. ${ }^{\circ} 59$ e n. $\left.{ }^{\circ} 88\right)$, Évora (n. ${ }^{\circ} 64$ e n. $\left.{ }^{\circ} 77\right)$, Viseu (n. $\left.{ }^{\circ} 67\right)$, Portalegre (n. ${ }^{\circ}$ 71) e Alentejo (.$\left.^{\circ} 75\right)$, indo ao encontro dos propósitos editoriais várias vezes enunciados de que esta publicação não se destinava à promoção de uma determinada região do país, mas à de todas elas. Para esse fim, "é enviada para todos os pontos do país e do estrangeiro onde de ante-mão sabemos que a sua leitura e as suas informações podem ter benéfico efeito, e para tanto traz ela os seus artigos publicados em várias línguas" (Pardal, 1937: 3).

Refira-se ainda uma outra matéria em que a revista Turismo terá sido pioneira, ao sugerir em 1949 um roteiro de "aldeias turísticas", inspirando-se no exemplo de Monsanto, a "aldeia mais portuguesa" à qual dedicara em março de 1939 um número especial:

O que podemos - e isto é tanto quanto possível viável - é procurar valorizar uma cidade, ou duas ou três aldeias entre todas e dar-lhes tudo o que elas necessitam para serem consideradas como autênticos pontos de turismo. Peguemos, por exemplo, na aldeia de Monsanto. Criemos boas estradas que conduzam o turista a ela; montemos um hotel ou 
uma grande pousada na aldeia ou muito próximo a ela. De seguida, trate-se de valorizar a terra escolhida, construindo, desfazendo, adaptando, realçando, em suma, todas as características e todo o seu valor. De seguida, faça-se publicidade no estrangeiro. E a aldeia será conhecida e visitada. A Suíça é célebre pela sua neve e pelos seus lagos. Tornese Portugal conhecido pelo seu Tejo, pelo seu Estoril, pelas suas «aldeias turísticas». (Melo, 1949: 53, itálico nosso).

Esta sugestão pode considerar-se precursora do programa das Aldeias Históricas, iniciado em 1991 com dez núcleos habitacionais de que faziam parte Almeida, Castelo Mendo, Castelo Novo, Castelo Rodrigo, Idanha-a-Velha, Linhares da Beira, Marialva, Monsanto, Piódão e Sortelha.

\section{Considerações finais}

Conforme ficou sublinhado no ponto anterior, a estratégia de propaganda turística assumida pela revista Turismo passou pela utilização de Mapas, ora abrangendo todo o território português, ora apresentando cartografias com roteiros turísticos regionais focados em zonas provinciais ou distritos. A incidência frequente em números monotemáticos, com informação muito alargada acerca dos distritos ou das regiões contempladas, fez igualmente parte dessa estratégia de promoção turística, do Minho ao Algarve, sendo justo reconhecer que se tratou de um notável esforço editorial pela riqueza de conteúdo desses "números especiais" que foram acompanhando as vicissitudes de uma publicação que não vivia de subsídios de qualquer espécie, apenas contando com "as receitas lícitas das assinaturas, da venda e dos seus anunciantes" (Seabra, 1943: s.p.).

É certo que essa "propaganda", por mais abrangente que tenha sido nos seus propósitos, implicava sempre uma seleção e hierarquização dos lugares sinalizados como dignos de serem vistos. Essa seleção, ignorando e omitindo outros que, por exclusão de partes, passam à categoria de inexistentes sob o prisma turístico, constitui um enorme risco de afunilamento que a crítica antiturística já havia assinalado a propósito da "cegueira turística" provocada pelos guias de viagem (Benjamin, 1980; Wittgenstein, como referido em Lauterbach, 1989; Debord, 1991; Cordeiro, 2007) e que, por analogia, poderia ser alargada, por exemplo, à limitação produzida pela classificação das chamadas "terras de turismo" na segunda década do século XX. Nesta perspetiva, poder-se-ia afirmar que, ao publicitar essas "terras", a imprensa turística se arriscava a ser responsabilizada por uma espécie de antituristização do território ao promover apenas aquilo que a intelligentsia turística portuguesa entendia como digno de ser visto. O que aconteceu no $2 .^{\circ}$ número da revista Turismo (maio de 1936) com a ilustração "Distancias em kilometros de Lisboa a's terras de turismo" e no $1 .^{\circ}$ número da revista Viagem (julho de 1938) com a ilustração "Porque não conhece Portugal?" pode ser catalogado na categoria de publicidade esporádica uma vez que, ao contrário de outras ilustrações, estas nunca mais surgiriam nas páginas dos citados periódicos. Com efeito, a "propaganda" subsequente aponta no sentido de um alargamento progressivo dos lugares turísticos e, por conseguinte, de uma indesmentível vontade de contribuir para a turistização do território. A imprensa turística configura-se, por conseguinte, como um dos participantes fundamentais na propaganda dos lugares, ajudando a 
transformá-los em destinos apetecíveis para os turistas nacionais e estrangeiros. A sua ação a este nível, como ficou suficientemente demonstrado, esteve, porém, longe de uma posição de neutralidade axiológica, atendendo a que o seu discurso corrobora a estratégia de inculcação dos principais valores defendidos pelo Estado Novo, indo ao ponto de veicular a glorificação da sua obra e do seu líder, como se pode ler no segundo número da série dedicada pela revista Turismo às Comemorações dos Centenários: "São oito séculos de independência que na parcela do tempo, numa epopeia imortal, conseguem despertar seus altos feitos e valor, traduzidos agora por esse vulto patriótico e magestoso que exalta Portugal pelo mundo inteiro, iluminando-o com o clarão do seu patriotismo e da sua inteligência: Salazar!” (Azevedo, 1940: s.p.).

Uma outra questão formulada na Introdução prende-se com a identificação do públicoalvo da revista Turismo. Da enunciação dos objetivos apresentados desde o primeiro Editorial se pode concluir que a mesma se destinava não apenas ao público interno, por excelência citadino e lisboeta, numa opção inegavelmente elitista, mas também ao leitor estrangeiro dos países com os quais Portugal mantinha mais afinidades, razão pela qual se encontram alguns artigos redigidos em francês, inglês, espanhol e alemão.

No cômputo geral, considera-se que este estudo, apesar das suas limitações no âmbito da análise comparativa já explicadas pela necessidade de delimitação do corpus e da própria extensão do artigo, pode trazer um contributo interessante para o conhecimento mais aprofundado da imprensa turística portuguesa no período em análise e do seu papel como elemento coadjuvante do desenvolvimento turístico nacional, ao potenciar fluxos para os diferentes lugares turísticos de Portugal.

Nesta área de estudo, há ideias suscitadas pela leitura dos periódicos em análise que são merecedoras de atenção em investigações futuras. Uma delas prende-se com a apologia de

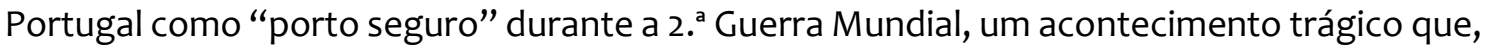
no dizer do jornalista Santana Quintinha (1940: s.p.), "acaba de dar-nos a expansão que uma publicidade de muitos anos dificilmente conseguiria". Partir deste quadro para um estudo comparativo entre o Portugal-oásis (1939-45) e o Portugal-destino-não-recomendado (2020) constitui um desafio estimulante e útil numa altura em que o nosso país, imediatamente após um período de grande euforia, se debate com uma crise sem precedentes na indústria turística.

\section{Referências}

Acciaiuoli, M. (2013). António Ferro: A vertigem da palavra. Lisboa: Editorial Bizâncio.

A 90 à hora. (1938, julho). Viagem: Revista de turismo, divulgação e cultura, I(1), 1.

A poesia da vida rústica ao serviço do Turismo. (1946, janeiro). Revista Turismo, X (66), s.p.

A visita do Director do Secretariado de Propaganda Nacional deu ensejo a interessantes afirmações sobre o muito que há a fazer em matéria de turismo. (1933, dezembro). ACP: Revista de Turismo e Automobilismo, III (39), 8-10.

Azevedo, C. (1940, fevereiro). Portugal ressurge! Turismo: Revista de Hoteis, Viagens e Actualidades, IV (29), s.p.

Benjamin, W. (1980 [1926]). Baedeker bedankt sich. In W. Benjamin, Gesammelte Schriften (p.450). Frankfurt am Main: Suhrkamp. 
Braga, P. (1936, abril). O Douro e o turismo em Trás-os-Montes. Turismo: Revista de Hoteis, Viagens e Actualidades, I(1), 12-13.

Cadavez, M. (2017). A bem da nação: As representações turísticas no Estado Novo entre 1933 e 1940. Edições 70.

Castro, M. J. (2014). Traços de viagem: A institucionalização do turismo na primeira metade do século XX. Tourism and Hospitality International Journal, 3(2), 41-54.

Centros de Repouso e Prazer (1937, fevereiro). Turismo: Revista de Hoteis, Viagens e Actualidades, I(6), 20.

Comissão Nacional do Centenário do Turismo em Portugal (2011, setembro). Mostra "Viagens pela Escrita e pelo Cartaz: 100 anos de Turismo em Portugal". Biblioteca Nacional de Portugal. Disponível

em: http://www.bnportugal.gov.pt/index.php?option=com_content\&view=article\&id=657\%3Amo stra-viagens-pela-escrita-100-anos-de-turismo-em-portugal.

Cordeiro, M. J. (2007). Hier ist die Zeit stehen geblieben. Olhares alemães: Portugal na literatura turística contemporânea. Guias de viagem e artigos de imprensa (1980-2006) (Tese de doutoramento). Universidade Nova de Lisboa. Lisboa.

Correia dos Santos, J. (1937, janeiro). Algarve, província de turismo. Turismo: Revista de Hoteis, Viagens e Actualidades, I(5), p. 6.

Crónica do Turismo. (1944, junho-julho). Turismo: Revista de Hoteis, Viagens e Actualidades, IX(58), s.p.

Debord, G. ([1967] 1991). A sociedade do espectáculo, (2 ed.). (Trad. F. Alves \& A. Monteiro). Lisboa: Mobilis in Mobile.

Estradas de Turismo e as comemorações do duplo centenário [Editorial]. Turismo: Revista de Hoteis, Viagens e Actualidades, III(23), s.p.

Façam campismo, rapazes e raparigas de Portugal (1944, abril-maio). Turismo: Revista de Hoteis, Viagens e Actualidades, IX(57), s.p.

Faia, Armando (1944, novembro-dezembro). Campismo turístico. Turismo: Revista de Hoteis, Viagens e Actualidades, IX(60), s.p.

Faia, Armando (1945, janeiro-fevereiro). Campismo turístico na região do Ribatejo. Turismo: Revista de Hoteis, Viagens e Actualidades, IX(61), s.p.

Ferreira, C. C. \& Simões, J. M. (2010). Portugal turístico ao tempo da I República: Espaços, lugares e projetos. In M. A. Lousada \& A. P. Pires (Eds.), Viajar. Viajantes e turistas à descoberta de Portugal no tempo da I República (pp. 77-98). Lisboa: Comissão Nacional para as Comemorações do Centenário da República.

Lauterbach, B. (1989). Baedeker und andere reiseführer - Eine Problemskizze. Zeitschrift fur Vokskünde, 85(2), 206-234.

Leal, J. (2000). Etnografias Portuguesas (1870-1970): Cultura popular e identidade nacional. Publicações Dom Quixote.

Maio, G. (1916, outubro 20). Conferência sobre Turismo. Revista de Turismo, I(8), 63-64.

Matos, A. C., Ribeiro, E. F. \& Bernardo, M. A. (2009). Caminhos-de-Ferro e turismo em Portugal (final do século XIX e primeiras décadas do século XX). Comunicação apresentada no V Congresso de História Ferroviária, Palma de Maiorca.

Melo, L. (1949, março-abril). Problemas de Turismo. Turismo: Revista de Hoteis, Viagens e Actualidades, XII(83), 52-53.

Número Especial de Aveiro. (1943, março-abril). Turismo: Revista de Hoteis, Viagens e Actualidades, VIII(52), s.p.

O $15 .^{\circ}$ ano da Revista A.C.P. [Editorial]. (1945, abril). ACP: Revista de Turismo e Automobilismo, XV(4), 316.

O Galo de Prata. (1938, setembro). Viagem: Revista de Turismo, Divulgação e Cultura, I(3), 1.

O Mapa Turístico de Portugal. (1945, novembro-dezembro). Turismo, Revista de Hotéis, Viagens e Actualidades, X(65), s.p. 
O que deve ver-se em Coimbra. (1944, janeiro-fevereiro). Turismo: Revista de Hoteis, Viagens e Actualidades, VIII(56), s.p.

Ornelas, C. (1940, novembro). Sinal de partida. Viagem: Revista de Turismo, Divulgação e Cultura, I(1), 1.

Pardal, A. (1937, fevereiro). "Turismo" e os Grémios Regionais. Turismo: Revista de Hoteis, Viagens e Actualidades, I(6), 3 .

Pinheiro, M. (2020, junho). O estado Novo foi completamente anticomboio / Entrevistada por Clara Teixeira. Visão História, 59, 46-49.

Porque vimos [Editorial] (1936, abril). Turismo: Revista de Hoteis, Viagens e Actualidades, I(1), 2.

Publicité dans «Turismo» (1937, fevereiro). Turismo: Revista de Hoteis, Viagens e Actualidades, I(6), 16.

Quintinha, J. (1936, abril). Visitai o Algarve. Turismo: Revista de Hoteis, Viagens e Actualidades, I(1), 8.

Quintinha, J. (1940, agosto-setembro). Os encantos do Minho. Turismo: Revista de Hoteis, Viagens e Actualidades, IV(35), s.p.

Quintinha, S. (1940, junho-julho). O elegante internacionalismo da Costa Do Sol. Turismo: Revista de Hoteis, Viagens e Actualidades, IV(33-34), s.p.

Ribeiro, C. (2017). Turismo ferroviário em Portugal nos anos de 1930. Dos Algarves: A Multidisciplinary e-Journal, 30,18-30. doi: 10.18089/DAMeJ.2017.30.2

Rocha, M. (1944, agosto-outubro). Setúbal - uma riqueza turística por explorar. Turismo: Revista de Hoteis, Viagens e Actualidades, IX(59), s.p.

Sampaio, J. (2012). Mitificação e paisagem simbólica: O caso do Estado Novo. Cadernos Curso de Doutoramento em Geografia da Faculdade de Letras do Porto, 101-122.

Santos, G. (2008). "Política do espírito": O bom gosto obrigatório para embelezar a realidade. Media \& Jornalismo, 12, 59-72.

Seabra, J. (1943, março-abril). O nosso aniversário. Turismo: Revista de Hoteis, Viagens e Actualidades, VIII(52), s.p.

Sociedade Propaganda de Portugal (s.d.) [1915]. Portugal: Clima, Paisagens, Estações Thermaes, etc. Lisboa: Sociedade Propaganda de Portugal.

Victorino, J. G. (2018). Panorama: Revista Portuguesa de Arte e Turismo. 1. ' Série, 1941-1949. Lisboa: Hemeroteca Municipal de Lisboa. Disponível em: http://hemerotecagdigital.cmlisboa.pt/Periodicos/Panorama/Panorama.htm.

Manuel Tojal de Meneses é doutor em Literatura Portuguesa pela Universidade de Toulouse - Le Mirail, com a tese Maria Velho da Costa: Un atelier d'écriture. Em 1989, foi-lhe concedida a equivalência ao Grau de Doutor na especialidade de Literatura Portuguesa, pela Faculdade de Letras da Universidade do Porto. É professor auxiliar no Instituto Universitário da Maia e no Instituto Politécnico da Maia. Atualmente é membro do N2i - Núcleo de Investigação do Instituto Politécnico da Maia. Os seus interesses de investigação incluem a Comunicação Digital, a Literatura de Viagens, o Turismo Literário e a Imprensa Turística. Endereço institucional: Instituto Politécnico da Maia (IPMAIA), Av. Carlos de Oliveira Campos, s/n, 4475-690 Avioso S. Pedro, Castêlo da Maia, Portugal. ORCID: 0000-0003-25831065.

Submetido em 20 de maio de 2020

Aceite em 11 de fevereiro de 2021 